\title{
Solvability of $(k, n-k)$ Conjugate Boundary Value Problems with Integral Boundary Conditions at Resonance
}

\author{
Qiao Sun ${ }^{1}$ and Yujun $\mathrm{Cui}^{2}$ \\ ${ }^{1}$ Department of Mathematics, Shandong University of Science and Technology, Qingdao 266590, China \\ ${ }^{2}$ State Key Laboratory of Mining Disaster Prevention and Control Co-Founded by Shandong Province and the Ministry of \\ Science and Technology, Shandong University of Science and Technology, Qingdao 266590, China
}

Correspondence should be addressed to Yujun Cui; cyj720201@163.com

Received 27 July 2016; Accepted 9 October 2016

Academic Editor: Enrique Llorens-Fuster

Copyright (C) 2016 Q. Sun and Y. Cui. This is an open access article distributed under the Creative Commons Attribution License, which permits unrestricted use, distribution, and reproduction in any medium, provided the original work is properly cited.

We investigate a $(k, n-k)$ conjugate boundary value problem with integral boundary conditions. By using Mawhin continuation theorem, we study the solvability of this boundary value problem at resonance. It is shown that the boundary value problem $(-1)^{n-k} \varphi^{(n)}(x)=f\left(x, \varphi(x), \varphi^{\prime}(x), \ldots, \varphi^{(n-1)}(x)\right), x \in[0,1], \varphi^{(i)}(0)=\varphi^{(j)}(1)=0,1 \leq i \leq k-1,0 \leq j \leq n-k-1, \varphi(0)=\int_{0}^{1} \varphi(x) d A(x)$ has at least one solution under some suitable conditions.

\section{Introduction}

In the past years, many authors have investigated the existence of solutions for $(k, n-k)$ conjugate boundary value problems at nonresonance (see [1-8]). They got the existence of solutions by using varying methods such as upper and lower solution method and fixed point theorem. For example, by using fixed point index theory, Zhang and Sun [6] investigated the existence of positive solutions for the following problem:

$$
\begin{aligned}
(-1)^{n-k} \varphi^{(n)}(x)=h(x) & f(\varphi(x)), \\
& 0<x<1, n \geq 2,1 \leq k \leq n-1,
\end{aligned}
$$

with the boundary conditions

$$
\begin{aligned}
\varphi(0) & =\sum_{i=1}^{m-2} a_{i} \varphi\left(\xi_{i}\right), \\
\varphi^{(i)}(0) & =\varphi^{(j)}(1)=0, \\
\varphi(1) & =\sum_{i=1}^{m-2} a_{i} \varphi\left(\xi_{i}\right),
\end{aligned}
$$

$$
\begin{aligned}
\varphi^{(i)}(0)=\varphi^{(j)}(1)=0, & \\
& 0 \leq i \leq k-1,1 \leq j \leq n-k-1 .
\end{aligned}
$$

The research on the solvability of boundary value problems at resonance has also been done by many people (see [9$15])$, but only a few people study the solvability of $(k, n-$ $k$ ) conjugate boundary value problems at resonance. For instance, in [9], Jiang and Qiu studied the existence of solutions for the following $(k, n-k)$ conjugate boundary value problem at resonance:

$$
\begin{aligned}
(-1)^{n-k} y^{(n)}(t) & =f\left(t, y(t), y^{\prime}(t), \ldots, y^{(n-1)}(t)\right), \\
t \in[0,1], & \\
y^{(i)}(0) & =y^{(j)}(1)=0, \\
0 & \leq i \leq k-1,0 \leq j \leq n-k-2, \\
y^{(n-1)}(1) & =\sum_{i=1}^{m} \alpha_{i} y^{(n-1)}\left(\xi_{i}\right),
\end{aligned}
$$

where $1 \leq k \leq n-1,0<\xi_{1}<\xi_{2}<\cdots<\xi_{m}<1$. 
Inspired by $[6,9]$, we shall discuss the solvability of the following $(k, n-k)$ conjugate boundary value problem at resonance:

$$
\begin{gathered}
(-1)^{n-k} \varphi^{(n)}(x)=f\left(x, \varphi(x), \varphi^{\prime}(x), \ldots, \varphi^{(n-1)}(x)\right), \\
x \in[0,1], \\
\varphi^{(i)}(0)=\varphi^{(j)}(1)=0, \\
1 \leq i \leq k-1,0 \leq j \leq n-k-1, \\
\varphi(0)=\int_{0}^{1} \varphi(x) d A(x),
\end{gathered}
$$

where $1 \leq k \leq n-1, n \geq 2, A(x)$ is right continuous on $[0,1)$ and left continuous at $x=1 ; \int_{0}^{1} u(x) d A(x)$ denotes the Riemann-Stieltjes integrals of $u$ with respect to $A$.

Different from the above results, the boundary condition we study is $\varphi(0)=\int_{0}^{1} \varphi(x) d A(x)$. As far as we are concerned, it is innovative to study the solvability of $(k, n-k)$ conjugate boundary value problem at resonance in the case $\varphi(0)=$ $\int_{0}^{1} \varphi(x) d A(x)$.

The organization of this paper is as follows. In Section 2, we provide Mawhin continuation theorem which will be used to prove the main results. In Section 3, we will give some lemmas and prove the solvability of problem (4).

\section{Preliminaries}

Firstly, for the convenience of the reader, we recall some definitions and notations.

Definition 1. Assume that $X$ and $Y$ be real Banach spaces and $L: \operatorname{dom} L \subset X \rightarrow Y$ be a Fredholm operator of index zero, if the following conditions hold: (1) Im $L$ is a closed subspace of $Y$; (2) $\operatorname{dim} \operatorname{ker} L=\operatorname{codim} \operatorname{Im} L<\infty$.

Let $X, Y$ be real Banach spaces and let $L: \operatorname{dom} L \subset X \rightarrow$ $Y$ be a Fredholm operator of index zero. $P: X \rightarrow X, Q: Y \rightarrow$ $Y$ are continuous projectors such that

$$
\begin{aligned}
\operatorname{Im} P & =\operatorname{ker} L, \\
\operatorname{ker} Q & =\operatorname{Im} L, \\
X & =\operatorname{ker} L \oplus \operatorname{ker} P, \\
Y & =\operatorname{Im} L \oplus \operatorname{Im} Q .
\end{aligned}
$$

It follows that

$$
\left.L\right|_{\operatorname{dom} L \cap \operatorname{ker} P}: \operatorname{dom} L \cap \operatorname{ker} P \longrightarrow \operatorname{Im} L
$$

is invertible. We denote the inverse of the mapping by $K_{P}$ (generalized inverse operator of $L$ ). If $\Omega$ is an open bounded subset of $X$ such that $\operatorname{dom} L \cap \Omega \neq \emptyset$, the mapping $N: X \rightarrow Y$ will be called $L$-compact on $\bar{\Omega}$ if $Q N(\bar{\Omega})$ is bounded and $K_{P}(I-Q) N: \bar{\Omega} \rightarrow X$ is compact.

Theorem 2 (see [16] (Mawhin continuation theorem)). Let $L: \operatorname{dom} L \subset X \rightarrow Y$ be a Fredholm operator of index zero and let $N$ be L-compact on $\bar{\Omega}$. The equation $L \varphi=N \varphi$ has at least one solution in $\operatorname{dom} L \cap \bar{\Omega}$ if the following conditions are satisfied:

(1) $L \varphi \neq \lambda N \varphi$ for every $(\varphi, \lambda) \in[(\operatorname{dom} L \backslash \operatorname{ker} L) \cap \partial \Omega] \times$ $(0,1)$;

(2) $N \varphi \notin \operatorname{Im} L$ for every $\varphi \in \operatorname{ker} L \cap \partial \Omega$;

(3) $\operatorname{deg}\left(\left.Q N\right|_{\text {ker } L}, \Omega \cap \operatorname{ker} L, 0\right) \neq 0$, where $Q: Y \rightarrow Y$ is a projection such that $\operatorname{Im} L=\operatorname{ker} Q$.

Let $X=C^{n-1}[0,1]$ with norm $\|u\|=\max \left\{\|u\|_{\infty},\left\|u^{\prime}\right\|_{\infty}\right.$, $\left.\ldots,\left\|u^{(n-1)}\right\|_{\infty}\right\}$ in which $\|u\|_{\infty}=\max _{x \in[0,1]}|u(x)|$. Let $Y=$ $L^{1}[0,1]$ with norm $\|x\|_{1}=\int_{0}^{1}|x(t)| d t$. Operator $L$ is defined as $L: L \varphi(x)=(-1)^{n-k} \varphi^{(n)}(x)$ with

$$
\begin{gathered}
\operatorname{dom} L=\left\{\varphi \in X: \varphi^{(i)}(0)=\varphi^{(j)}(1)=0,1 \leq i \leq k\right. \\
\left.-1,0 \leq j \leq n-k-1, \varphi(0)=\int_{0}^{1} \varphi(x) d A(x)\right\} .
\end{gathered}
$$

Define operator $N: X \rightarrow Y$ as follows:

$$
(N \varphi)(x)=f\left(x, \varphi(x), \varphi^{\prime}(x), \ldots, \varphi^{(n-1)}(x)\right) .
$$

So problem (4) becomes $L \varphi=N \varphi$.

\section{Main Results}

Assume that the following conditions hold in this paper:

(H1) $\int_{0}^{1} \Phi_{1}(x) d A(x)=1, \Delta=\int_{0}^{1} \int_{0}^{1} k(x, y) d y d A(x) \neq 0$, where

$$
\begin{aligned}
& k(x, y)= \begin{cases}\frac{1}{(k-1) !(n-k-1) !} \int_{0}^{x(1-y)} t^{k-1}(t+y-x)^{n-k-1} d t, & 0 \leq x \leq y \leq 1 ; \\
\frac{1}{(k-1) !(n-k-1) !} \int_{0}^{y(1-x)} t^{n-k-1}(t+x-y)^{k-1} d t, & 0 \leq y \leq x \leq 1,\end{cases} \\
& \Phi_{1}(x)=\frac{(n-1) !}{(k-1) !(n-k-1) !} \int_{x}^{1} t^{k-1}(1-t)^{n-k-1} d t .
\end{aligned}
$$


(H2) $f:[0,1] \times R^{n} \rightarrow R$ satisfies Caratháodory conditions.

(H3) There exist functions $r(x), q_{i}(x) \in L^{1}[0,1]$ with $\sum_{i=1}^{n}\left\|q_{i}\right\|_{1}<1$ such that

$$
\begin{aligned}
\left|f\left(x, \varphi_{1}, \varphi_{2}, \ldots, \varphi_{n}\right)\right| \leq \sum_{i=1}^{n} q_{i}(x)\left|\varphi_{i}\right| & +r(x), \\
x & \in[0,1], \varphi_{i} \in R .
\end{aligned}
$$

(H4) There exists a constant $M>0$ such that if $\left|\varphi^{(n-1)}(x)\right|>$ $M, x \in[0,1]$, then

$$
\begin{gathered}
\int_{0}^{1} \int_{0}^{1} k(x, y) f\left(y, \varphi(y), \varphi^{\prime}(y), \varphi^{\prime \prime}(y), \ldots\right. \\
\left.\varphi^{(n-1)}(y)\right) d y d A(x) \neq 0 .
\end{gathered}
$$

(H5) There is a constant $a_{0}>0$ such that either

$$
\begin{aligned}
& c \int_{0}^{1} \int_{0}^{1} k(x, y) f\left(y, c \Phi_{1}(y), c \Phi_{1}^{\prime}(y), c \Phi_{1}^{\prime \prime}(y), \ldots,\right. \\
& \left.c \Phi_{1}^{(n-1)}(y)\right) d y d A(x)<0 \\
& \quad \text { or } \\
& c \int_{0}^{1} \int_{0}^{1} k(x, y) f\left(y, c \Phi_{1}(y), c \Phi_{1}^{\prime}(y), c \Phi_{1}^{\prime \prime}(y), \ldots,\right. \\
& \left.c \Phi_{1}^{(n-1)}(y)\right) d y d A(x)>0 \\
& \text { holds if }|c|>a_{0} .
\end{aligned}
$$

Then we can present the following theorem.

Theorem 3. Suppose that (H1)-(H5) are satisfied; then there must be at least one solution of problem (4) in X.

To prove the theorem, we need the following lemmas.

Lemma 4. Assume that (H1) holds; then $L: \operatorname{dom} L \subset X \rightarrow Y$ is a Fredholm operator with index zero. And a linear continuous projector $Q: Y \rightarrow Y$ can be defined by

$$
(Q u)(x)=\frac{1}{\Delta} \int_{0}^{1} \int_{0}^{1} k(x, y) u(y) d y d A(x)
$$

Furthermore, define a linear operator $K_{P}: \operatorname{Im} L \rightarrow \operatorname{dom} L \cap$ ker $P$ as follows:

$$
\begin{aligned}
\left(K_{P} u\right)(x)= & \int_{0}^{1} k(x, y) u(y) d y \\
& +\Phi_{1}(x) \int_{0}^{1} \int_{0}^{1} k(x, y) u(y) d y d A(x)
\end{aligned}
$$

Proof. It follows from (10) that

$$
\begin{aligned}
(-1)^{n-k} \Phi_{1}^{(n)}(x) & =0, \quad x \in[0,1], \\
\Phi_{1}^{(i)}(0) & =\Phi_{1}^{(j)}(1)=0, \\
& 1 \leq i \leq k-1,0 \leq j \leq n-k-1, \\
\Phi_{1}(0) & =\int_{0}^{1} \Phi_{1}(x) d A(x) .
\end{aligned}
$$

Thus we have

$$
\operatorname{ker} L=\left\{c \Phi_{1}(x), c \in R\right\}
$$

Moreover, we can obtain that

$$
\operatorname{Im} L=\left\{u \in Y: \int_{0}^{1} \int_{0}^{1} k(x, y) u(y) d y d A(x)=0\right\} .
$$

On one hand, suppose $u \in \operatorname{Im} L$; then there exists $\varphi \in \operatorname{dom} L$ such that

$$
u=L \varphi \in Y
$$

Then we have

$$
\varphi(x)=\int_{0}^{1} k(x, y) u(y) d y+\varphi(0) \Phi_{1}(x) .
$$

Furthermore, for $\varphi \in \operatorname{dom} L$,

$$
\begin{aligned}
\varphi(0) & =\int_{0}^{1} \varphi(x) d A(x) \\
= & \int_{0}^{1}\left[\int_{0}^{1} k(x, y) u(y) d y+\varphi(0) \Phi_{1}(x)\right] d A(x) \\
= & \int_{0}^{1} \int_{0}^{1} k(x, y) u(y) d y d A(x) \\
& +\varphi(0) \int_{0}^{1} \Phi_{1}(x) d A(x)
\end{aligned}
$$

By this together with (H1) we can get

$$
\varphi(0)=\int_{0}^{1} \int_{0}^{1} k(x, y) u(y) d y d A(x)+\varphi(0),
$$

which means $\int_{0}^{1} \int_{0}^{1} k(x, y) u(y) d y d A(x)=0$. So we obtain that

$$
\operatorname{Im} L \subset\left\{u: \int_{0}^{1} \int_{0}^{1} k(x, y) u(y) d y d A(x)=0\right\} .
$$

On the other hand, if $u \in Y$ satisfies $\int_{0}^{1} \int_{0}^{1} k(x, y) u(y) d y d A(x)=0$, we let

$$
\varphi(x)=\int_{0}^{1} k(x, y) u(y) d y+\Phi_{1}(x) .
$$


Then we conclude that

$$
\begin{aligned}
L \varphi(x) & =(-1)^{n-k} \varphi^{(n)}(x)=u(x), \\
\varphi(0) & =\int_{0}^{1} k(0, y) u(y) d y+\Phi_{1}(0)=1 .
\end{aligned}
$$

Besides,

$$
\begin{aligned}
\int_{0}^{1} \varphi(x) d A(x)= & \int_{0}^{1} \int_{0}^{1} k(x, y) u(y) d y d A(x) \\
& +\int_{0}^{1} \Phi_{1}(x) d A(x)=1 ;
\end{aligned}
$$

therefore

$$
\begin{aligned}
& \varphi(0)=\int_{0}^{1} \varphi(x) d A(x), \\
& \varphi^{(i)}(0)=\varphi^{(j)}(1)=0, \\
& \quad 1 \leq i \leq k-1,0 \leq j \leq n-k-1 .
\end{aligned}
$$

That is, $\varphi \in \operatorname{dom} L$; then $u \in \operatorname{Im} L$. In conclusion,

$$
\operatorname{Im} L=\left\{u \in Y: \int_{0}^{1} \int_{0}^{1} k(x, y) u(y) d y d A(x)=0\right\} .
$$

We define a linear operator $P: X \rightarrow X$ as

$$
(P \varphi)(x)=\Phi_{1}(x) \varphi(0) .
$$

It is obvious that $P^{2} \varphi=P \varphi$ and $\operatorname{Im} P=\operatorname{ker} L$. For any $\varphi \in X$, together with $\varphi=(\varphi-P \varphi)+P \varphi$, we have $X=\operatorname{ker} P+\operatorname{ker} L$. It is easy to obtain that $\operatorname{ker} L \cap \operatorname{ker} P=\{0\}$ which implies

$$
X=\operatorname{ker} P \oplus \operatorname{ker} L \text {. }
$$

Next operator $Q: Y \rightarrow Y$ is defined as follows:

$$
(Q u)(x)=\frac{1}{\Delta} \int_{0}^{1} \int_{0}^{1} k(x, y) u(y) d y d A(x) .
$$

Noting that

$$
\begin{aligned}
& \left(Q^{2} u\right)(x)=(Q(Q u))(x)=\frac{1}{\Delta} \int_{0}^{1} \int_{0}^{1} k(x, y) \\
& \cdot\left[\frac{1}{\Delta} \int_{0}^{1} \int_{0}^{1} k(x, y) u(y) d y d A(x)\right] d y d A(x) \\
& =\frac{1}{\Delta} \int_{0}^{1} \int_{0}^{1} k(x, y) d y d A(x) \frac{1}{\Delta} \int_{0}^{1} \int_{0}^{1} k(x, y) \\
& \cdot u(y) d y d A(x)=(Q u)(x),
\end{aligned}
$$

it means $Q$ is a projection operator. And obviously, $\operatorname{ker} Q=$ $\operatorname{Im} L$. For any $u \in Y$, because $u=(u-Q u)+Q u$, we have $Y=\operatorname{Im} L+\operatorname{Im} Q$. Moreover, by simple calculation, we can get $\operatorname{Im} Q \cap \operatorname{Im} L=\{0\}$. Above all, $Y=\operatorname{Im} L \oplus \operatorname{Im} Q$.

To sum up we can get that $\operatorname{Im} L$ is a closed subspace of $Y$; $\operatorname{dim} \operatorname{ker} L=\operatorname{codim} \operatorname{Im} L<+\infty$; that is, $L$ is a Fredholm operator of index zero.
We now define operator $K_{P}: Y \rightarrow X$ as follows:

$$
\begin{aligned}
\left(K_{P} u\right)(x)= & \int_{0}^{1} k(x, y) u(y) d y \\
& +\Phi_{1}(x) \int_{0}^{1} \int_{0}^{1} k(x, y) u(y) d y d A(x) .
\end{aligned}
$$

For any $u \in \operatorname{Im} L$, we have $\int_{0}^{1} \int_{0}^{1} k(x, y) u(y) d y d A(x)=0$. Consequently,

$$
\left(K_{P} u\right)(x)=\int_{0}^{1} k(x, y) u(y) d y .
$$

So

$$
\left(K_{P} u\right)(0)=0=\int_{0}^{1}\left(K_{P} u\right)(x) d A(x),
$$

$$
\left(K_{P} u\right)(x) \in \operatorname{ker} P \text {. }
$$

In addition, it is easy to know that

$$
\begin{aligned}
& \left(K_{P} u\right)^{(i)}(0)=0, \quad 1 \leq i \leq k-1 ; \\
& \left(K_{P} u\right)^{(j)}(1)=0, \quad 0 \leq j \leq n-k-1 ;
\end{aligned}
$$

then $\left(K_{P} u\right)(x) \in \operatorname{dom} L$. Therefore

$$
K_{P} u \in \operatorname{dom} L \cap \operatorname{ker} P, \quad u \in \operatorname{Im} L .
$$

Next we will prove that $K_{P}$ is the inverse of $\left.L\right|_{\operatorname{dom} L n \operatorname{ker} P}$. It is clear that

$$
\left(L K_{P} u\right)(x)=u(x), \quad u \in \operatorname{Im} L .
$$

For each $y \in \operatorname{dom} L \cap \operatorname{ker} P$, we have $y(0)=0$ and

$$
\begin{aligned}
& \left(K_{P} L y\right)(x) \\
& =y(x)-y(0) \Phi_{1}(x) \\
& \quad+\Phi_{1}(x) \int_{0}^{1}\left(y(x)-y(0) \Phi_{1}(x)\right) d A(x) \\
& =\left(y(x)-y(0) \Phi_{1}(x)\right)+y(0) \Phi_{1}(x) \\
& \quad-y(0) \Phi_{1}(x) \int_{0}^{1} \Phi_{1}(x) d A(x)=y(x) .
\end{aligned}
$$

This implies that $K_{P} L y=y$. So $K_{P}=\left(\left.L\right|_{\operatorname{dom} L \cap \operatorname{ker} P}\right)^{-1}$. Thus the lemma holds.

Lemma 5. $N$ is L-compact on $\bar{\Omega}$ if $\operatorname{dom} L \cap \bar{\Omega} \neq 0$, where $\Omega$ is a bounded open subset of $X$.

Proof. We can get easily that $Q N(\bar{\Omega})$ is bounded. By Lebesgue dominated convergence theorem and condition (H2), we have that $K_{P}(I-Q) N(\bar{\Omega})$ is bounded. In addition, for

$$
\begin{aligned}
& \left\{\int_{0}^{1} k(x, y)(I-Q) N(y) d y\right. \\
& \left.\quad+\Phi_{1}(x) \int_{0}^{1} \int_{0}^{1} k(x, y)(I-Q) N(y) d y d A(x)\right\}
\end{aligned}
$$


is equicontinuous, by Ascoli-Arzela theorem, we get $K_{P}(I-$ Q) $N: \bar{\Omega} \rightarrow X$ is compact. Thus, $N$ is $L$-compact. The proof is completed.

Lemma 6. The set $\Omega_{1}=\{\varphi \in \operatorname{dom} L \backslash \operatorname{ker} L: L \varphi=\lambda N \varphi, \lambda \in$ $[0,1]\}$ is bounded if (H1)-(H4) are satisfied.

Proof. Take $\varphi \in \Omega_{1}$; then $N \varphi \in \operatorname{Im} L$. Thus we have

$$
\begin{gathered}
\int_{0}^{1} \int_{0}^{1} k(x, y) f\left(y, \varphi(y), \varphi^{\prime}(y), \ldots\right. \\
\left.\varphi^{(n-1)}(y)\right) d y d A(x)=0
\end{gathered}
$$

and $\varphi^{(i)}(0)=\varphi^{(j)}(1)=0,1 \leq i \leq k-1,0 \leq j \leq$ $n-k-1$. Hence there exists at least a point $\theta_{i} \in[0,1]$, such that $\varphi^{(i)}\left(\theta_{i}\right)=0, i=1,2, \ldots, n-2$. Thus, we get $\varphi^{(i)}(x)=\int_{\theta_{i}}^{x} \varphi^{(i+1)}(t) d t, i=0,1,2, \ldots, n-2$. So,

$$
\begin{aligned}
& \left\|\varphi^{(i)}\right\|_{\infty} \leq\left\|\varphi^{(i+1)}\right\|_{1} \leq\left\|\varphi^{(i+1)}\right\|_{\infty}, \\
& i=0,1,2, \ldots, n-2 .
\end{aligned}
$$

It follows from (42) and condition (H4) that there exists one point $x_{0} \in[0,1]$ such that

$$
\left|\varphi^{(n-1)}\left(x_{0}\right)\right| \leq M .
$$

From

$$
\begin{aligned}
& \left\|\varphi^{(n-1)}(x)\right\|_{\infty}=\max _{x \in[0,1]}\left|\varphi^{(n-1)}(x)\right|, \\
& \varphi^{(n-1)}(x)=\varphi^{(n-1)}\left(x_{0}\right)+\int_{x_{0}}^{x} \varphi^{(n)}(t) d t \\
& =\varphi^{(n-1)}\left(x_{0}\right) \\
& \quad+\int_{x_{0}}^{x}(-1)^{n-k} f\left(t, \varphi(t), \varphi^{\prime}(t), \ldots, \varphi^{(n-1)}(t)\right) d t
\end{aligned}
$$

it follows that

$$
\begin{aligned}
\left|\varphi^{(n-1)}(x)\right| & \leq\left|\varphi^{(n-1)}\left(x_{0}\right)\right|+\int_{x_{0}}^{x}\left|\varphi^{(n)}(t)\right| d t \\
& \leq M+\sum_{i=1}^{n}\left\|q_{i}\right\|_{1}\left\|\varphi^{(i-1)}\right\|_{\infty}+\|r\|_{1} \\
& \leq M+\sum_{i=1}^{n}\left\|q_{i}\right\|_{1}\left\|\varphi^{(n-1)}\right\|_{\infty}+\|r\|_{1} .
\end{aligned}
$$

Therefore, we can obtain that

$$
\left\|\varphi^{(n-1)}\right\|_{\infty} \leq \frac{M+\|r\|_{1}}{1-\sum_{i=1}^{n-1}\left\|q_{i}\right\|_{1}} .
$$

By (43) we know

$$
\left\|\varphi^{(i)}\right\|_{\infty} \leq \frac{M+\|r\|_{1}}{1-\sum_{i=1}^{n-1}\left\|q_{i}\right\|_{1}}, \quad i=0,1,2, \ldots, n-1 .
$$

Then $\Omega_{1}$ is bounded. The proof of the lemma is completed.
Lemma 7. The set $\Omega_{2}=\{\varphi: \varphi \in \operatorname{ker} L, N \varphi \in \operatorname{Im} L\}$ is bounded if (H1), (H2), and (H5) hold.

Proof. Let $\varphi \in \Omega_{2}$; then $\varphi(x) \equiv c \Phi_{1}(x)$ and $N \varphi \in \operatorname{Im} L$, so we can get

$$
\begin{gathered}
c \int_{0}^{1} \int_{0}^{1} f\left(y, c \Phi_{1}(y), c \Phi_{1}^{\prime}(y), c \Phi_{1}^{\prime \prime}(y), \ldots,\right. \\
\left.c \Phi_{1}^{(n-1)}(y)\right) d y d A(x)=0 .
\end{gathered}
$$

According to (H5) we have $|c| \leq a_{0}$; that is to say, $\Omega_{2}$ is bounded. We complete the proof.

Lemma 8. The set $\Omega_{3}=\{\varphi \in \operatorname{ker} L: \lambda J \varphi+\alpha(1-\lambda) Q N \varphi=$ $0, \lambda \in[0,1]\}$ is bounded if conditions (H1), (H2), and (H5) are satisfied, where $J: \operatorname{ker} L \rightarrow \operatorname{Im} L$ is a linear isomorphism, and

$$
\alpha= \begin{cases}-1, & \text { if (13) holds } \\ 1, & \text { if (14) holds }\end{cases}
$$

Proof. Suppose that $\varphi \in \Omega_{3}$; we have $\varphi(x)=c \Phi_{1}(x)$, and

$$
\begin{aligned}
\lambda c & +\alpha(1-\lambda) \int_{0}^{1} \int_{0}^{1} k(x, y) f\left(y, c \Phi_{1}(y), c \Phi_{1}^{\prime}(y),\right. \\
& \left.c \Phi_{1}^{\prime \prime}(y), \ldots, c \Phi_{1}^{(n-1)}(y)\right) d y d A(x) \\
& =0 .
\end{aligned}
$$

If $\lambda=0$, by condition (H5), we have $|c| \leq a_{0}$. If $\lambda=1$, then $c=0$. If $\lambda \in(0,1)$, we suppose $|c| \geq a_{0}$, and then

$$
\begin{aligned}
& \lambda c^{2}=-\alpha(1-\lambda) c \int_{0}^{1} \int_{0}^{1} f\left(y, c \Phi_{1}(y), c \Phi_{1}^{\prime}(y)\right. \\
& \left.c \Phi_{1}^{\prime \prime}(y), \ldots, c \Phi_{1}^{(n-1)}(y)\right) d y d A(x) \\
& \quad<0
\end{aligned}
$$

which contradicts $\lambda c^{2}>0$. So the lemma holds.

Then Theorem 3 can be proved now.

Proof of Theorem 3. Suppose that $\Omega \supset \bigcup_{i=1}^{3} \overline{\Omega_{i}} \cup\{0\}$ is a bounded open subset of $X$; from Lemma 5 we know that $N$ is $L$-compact on $\bar{\Omega}$. In view of Lemmas 6 and 7 we can get

(1) $L \varphi \neq \lambda N \varphi$, for every $(\varphi, \lambda) \in[(\operatorname{dom} L \backslash \operatorname{ker} L) \cap \partial \Omega] \times$ $(0,1)$;

(2) $N \varphi \notin \operatorname{Im} L$, for every $\varphi \in \operatorname{ker} L \cap \partial \Omega$.

Set $H(\varphi, \lambda)=\lambda J \varphi+\alpha(1-\lambda) Q N \varphi$. It follows from Lemma 8 that we have $H(\varphi, \lambda) \neq 0$ for any $\varphi \in \partial \Omega \cap$ ker $L$. So by the homotopy of degree, we have

$$
\begin{aligned}
& \operatorname{deg}\left(\left.Q N\right|_{\text {ker } L}, \Omega \cap \operatorname{ker} L, 0\right)=\operatorname{deg}(\alpha J, \Omega \cap \operatorname{ker} L, 0) \\
& \quad \neq 0 .
\end{aligned}
$$

All the conditions of Theorem 2 are satisfied. So there must be at least one solution of problem (4) in $X$. The proof of Theorem 3 is completed. 


\section{Example}

To illustrate our main theorem, we present the following example. Consider the boundary value problem

$$
\begin{aligned}
\varphi^{(4)}(x)= & \frac{1}{6} \sin \varphi(x)+\frac{1}{4}\left|\varphi^{\prime}(x)\right|+\frac{1}{4} \sin \varphi^{\prime \prime}(x) \\
& +\frac{1}{4} \varphi^{(3)}(x)+x-1, \quad x \in[0,1], \\
\varphi(0)= & 2 \int_{0}^{1} \varphi(x) d x, \\
\varphi^{\prime}(0)= & \varphi(1)=\varphi^{\prime}(1)=0 .
\end{aligned}
$$

Obviously, $n=4, k=2, A(x)=2 x$. Let $\Phi_{1}(x)=2 x^{3}-3 x^{2}+1$; then $2 \int_{0}^{1} \Phi_{1}(x) d x=1$; thus it is at resonance. Let

$$
\begin{aligned}
f\left(x, \varphi, \varphi^{\prime}, \varphi^{\prime \prime}, \varphi^{\prime \prime \prime}\right)= & \frac{1}{6} \sin \varphi+\frac{1}{4}\left|\varphi^{\prime}\right|+\frac{1}{4} \sin \varphi^{\prime \prime} \\
& +\frac{1}{4} \varphi^{\prime \prime \prime}+x-1
\end{aligned}
$$

then

$$
\begin{aligned}
\left|f\left(x, \varphi, \varphi^{\prime}, \varphi^{\prime \prime}, \varphi^{\prime \prime \prime}\right)\right| \leq & \frac{1}{6}|\varphi|+\frac{1}{4}\left|\varphi^{\prime}\right|+\frac{1}{4}\left|\varphi^{\prime \prime}\right| \\
& +\frac{1}{4}\left|\varphi^{\prime \prime \prime}\right|+1,
\end{aligned}
$$

where $q_{1}=1 / 6, \quad q_{2}=1 / 4, \quad q_{3}=1 / 4, q_{4}=1 / 4, r(x)=$ 1. Taking $M=6$, then we have $\left|\varphi^{\prime \prime \prime}(x)\right|>6$, and we can obtain $f\left(x, \varphi, \varphi^{\prime}, \varphi^{\prime \prime}, \varphi^{\prime \prime \prime}\right)>0$. This together with the fact that $k(x, y)>0$ for $x, y \in(0,1)$ implies

$$
\begin{gathered}
2 \int_{0}^{1} \int_{0}^{1} k(x, y) f\left(y, \varphi(y), \varphi^{\prime}(y), \varphi^{\prime \prime}(y),\right. \\
\left.\varphi^{\prime \prime \prime}(y)\right) d y d x>0 .
\end{gathered}
$$

That is, (H4) holds. Finally, taking $a_{0}=1$, when $c>1$, we obtain

$$
\begin{aligned}
& 2 c \int_{0}^{1} \int_{0}^{1} k(x, y) f\left(y, c \Phi_{1}(y), c \Phi_{1}^{\prime}(y), c \Phi_{1}^{\prime \prime}(y),\right. \\
& \left.c \Phi_{1}^{\prime \prime \prime}(y)\right) d y d x>0
\end{aligned}
$$

then condition (H5) is satisfied. It follows from Theorem 3 that the boundary value problem (54) has at least one solution in $C^{3}[0,1]$.

\section{Competing Interests}

The authors declare that they have no competing interests.

\section{Acknowledgments}

The project was supported by NNSF of China (11371221, 11571207), the Specialized Research Foundation for the Doctoral Program of Higher Education of China (20123705110001), the Program for Scientific Research Innovation Team in Colleges and Universities of Shandong Province, and the Tai'shan Scholar Engineering Construction Fund of Shandong Province of China.

\section{References}

[1] W. Jiang and J. Zhang, "Positive solutions for $(k, n-k)$ conjugate eigenvalue problems in Banach spaces," Nonlinear Analysis: Theory, Methods \& Applications, vol. 71, no. 3-4, pp. 723-729, 2009.

[2] R. P. Agarwal and D. O’Regan, "Positive solutions for ( $p, n-$ p) conjugate boundary-value problems," Journal of Differential Equations, vol. 150, no. 2, pp. 462-473, 1998.

[3] R. P. Agarwal and D. O’Regan, "Multiplicity results for singular conjugate, focal, and $(N, P)$ problems," Journal of Differential Equations, vol. 170, no. 1, pp. 142-156, 2001.

[4] Y. Cui and Y. Zou, "Monotone, iterative technique for $(k, n-$ $k$ ) conjugate boundary value problems," Electronic Journal of Qualitative Theory of Differential Equations, no. 69, pp. 1-11, 2015.

[5] X. He and W. Ge, "Positive solutions for semipositone $(p, n-p)$ right focal boundary value problems," Applicable Analysis. An International Journal, vol. 81, no. 2, pp. 227-240, 2002.

[6] G. W. Zhang and J. X. Sun, "Positive solutions of singular $(k, n-$ k) multi-point boundary value problems," Acta Mathematica Sinica, vol. 49, no. 2, pp. 391-398, 2006 (Chinese).

[7] D. Jiang, "Positive solutions to $(k, n-k)$ conjugate boundaryvalue problems," Acta Mathematica Sinica, vol. 44, pp. 541-548, 2001.

[8] R. Ma, "Positive solutions for semipositone $(k, n-k)$ conjugate boundary value problems," Journal of Mathematical Analysis and Applications, vol. 252, no. 1, pp. 220-229, 2000.

[9] W. Jiang and J. Qiu, "Solvability of $(k, n-k)$ conjugate boundaryvalue problems at resonance," Electronic Journal of Differential Equations, No. 114, 10 pages, 2012.

[10] W. Jiang, "Existence of solutions for $(k, n-k-2)$ conjugate boundary-value problems at resonance with $\operatorname{dim} \operatorname{kerL}=2$," Electronic Journal of Differential Equations, vol. 226, pp. 1-11, 2013.

[11] Y. Liu and W. Ge, "Solvability of nonlocal boundary-value problems for ordinary differential equations of higher order," Nonlinear Analysis. Theory, Methods \& Applications. An International Multidisciplinary Journal. Series A: Theory and Methods, vol. 57, no. 3, pp. 435-458, 2004.

[12] R. Ma, "Existence results of a $m$-point boundary-value problem at resonance," Journal of Mathematical Analysis and Applications, vol. 294, no. 1, pp. 147-157, 2004.

[13] C. Y. Xue and W. G. Ge, "Existence of solutions to multi-point boundary value problems at resonance," Acta Mathematica Sinica. Chinese Series, vol. 48, no. 2, pp. 281-290, 2005.

[14] X. Zhang, M. Feng, and W. Ge, "Existence result of second-order differential equations with integral boundary conditions at resonance," Journal of Mathematical Analysis and Applications, vol. 353, no. 1, pp. 311-319, 2009.

[15] W. Feng and J. R. L. Webb, "Solvability of three point boundary value problems at resonance," Nonlinear Analysis: Theory, Methods \& Applications, vol. 30, no. 6, pp. 3227-3238, 1997. 
[16] J. Mawhin, Topological Degree Methods in Nonlinear BoundaryValue Problems, Nsfcbms Regional Conference Series in Mathematics, American Mathematical Society, Providence, RI, USA, 1979. 


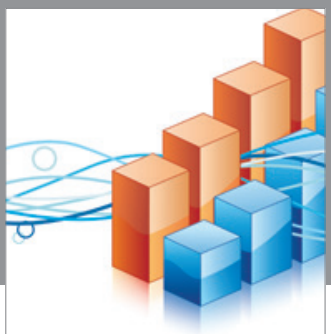

Advances in

Operations Research

vatem alat4

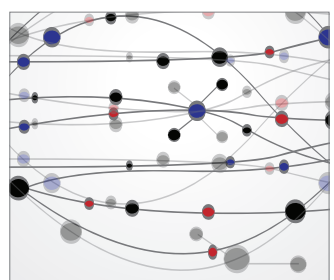

\section{The Scientific} World Journal
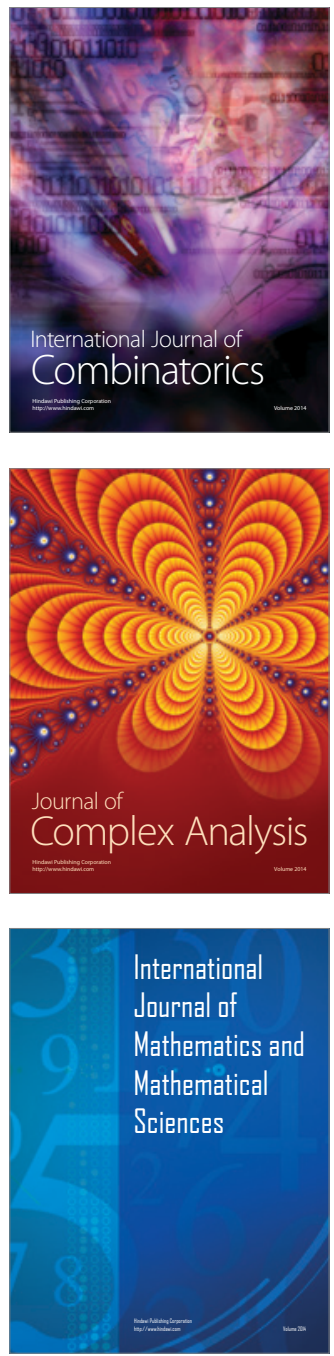
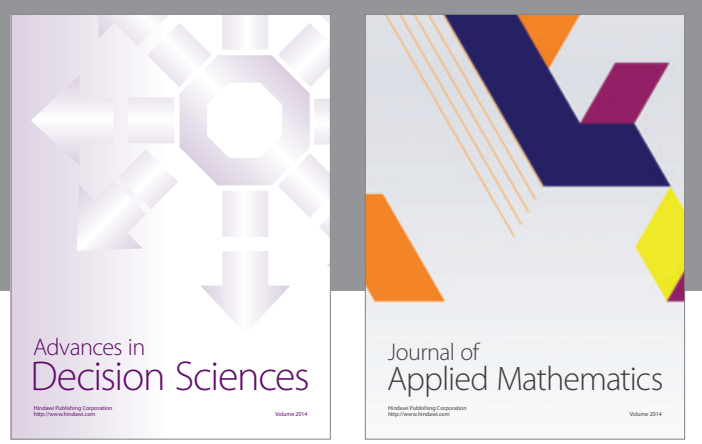

Algebra

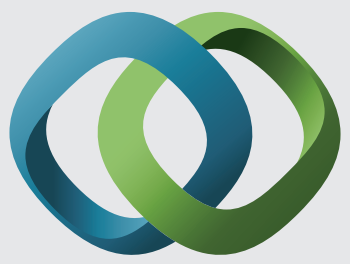

\section{Hindawi}

Submit your manuscripts at

http://www.hindawi.com
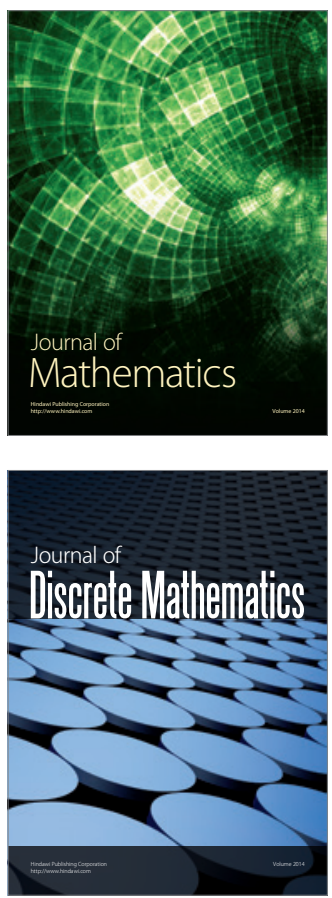

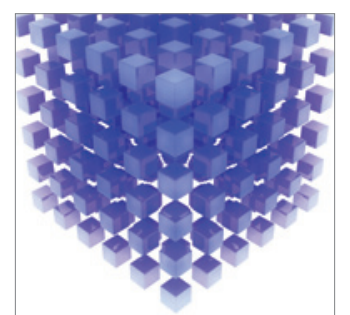

Mathematical Problems in Engineering
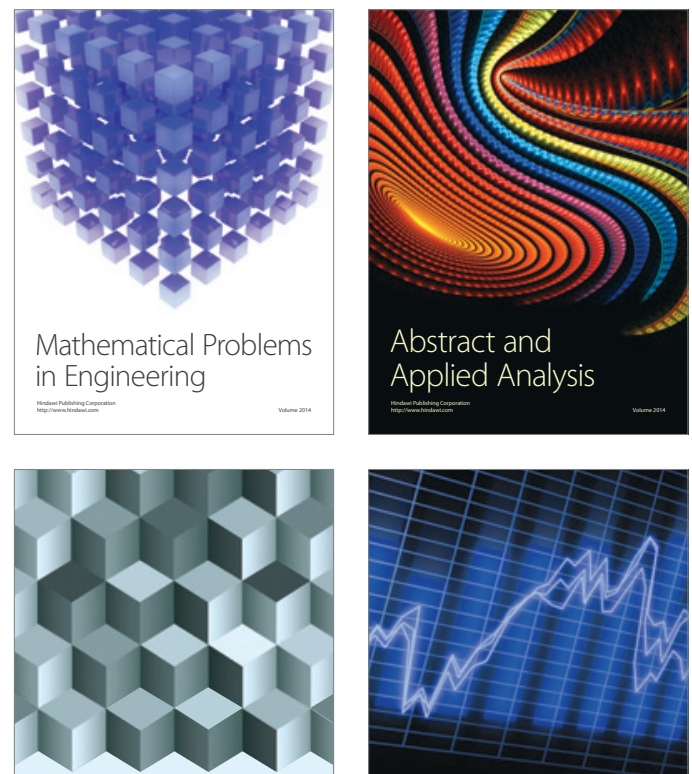

Journal of

Function Spaces

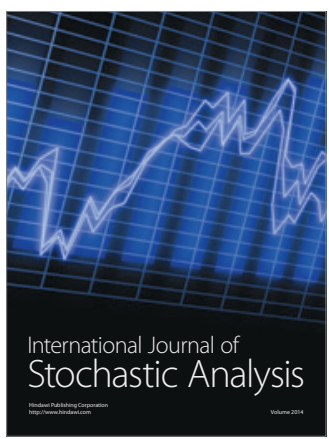

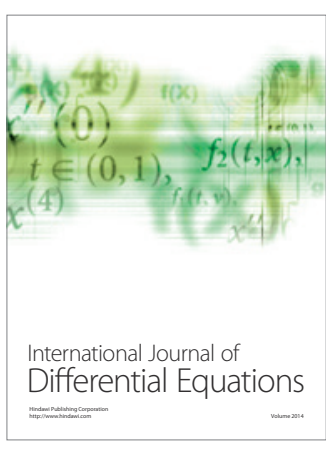
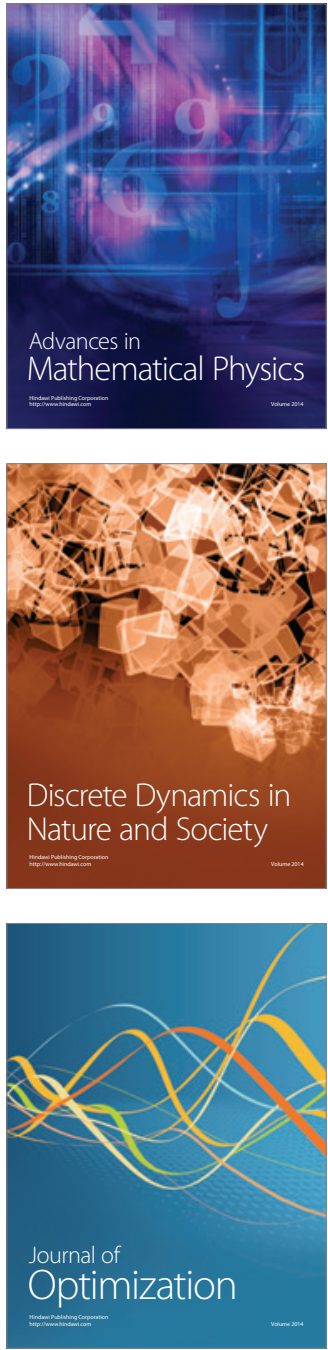